\title{
If Appleseed Had an Open Portal: Making Sense of Data, SEIS and Integrated Systems for the Maltese Islands
}

\author{
Saviour Formosa \\ Department of Criminology, Faculty for Social Wellbeing, University of Malta, \\ Humanities B, Msida MSD 2080 \\ saviour.formosa@um.edu.mt
}

\begin{abstract}
Much sought and realistically distant, an open data system can serve as the Holy Grail for many a policy-maker and decision taker as well as the operational entities involved in the field. The steady seeding of data-related legislative tools has aided the setting up of exploratory and active systems that serve the concept of data-information-knowledge-action to academia, the general public and the implementing agencies. Legislation, inclusive of Data Protection, Freedom of Information, Public Sector Information, Aarhus, INSPIRE, SEIS and the still embryonic SENSE, have all managed to create a new reality that may be too complex for some still caught in a jurassic analogue stage where data hoarding might still be prevalent and little effort is made to jump to the post-modern reality. Efforts to push the process through various domains such as census, environment protection, spatial development and crime have helped the Maltese Islands to create a scenario that is ripe for a national data infrastructure, inter-entity data exchange, open data structuring, and free dissemination services. This process enhances the knowledge-base and reduces redundancy, whilst creating new challenges on how to make sense of all the data being made available, particularly in the interpretation or misinterpretation of the outputs. The paper reviews Malta's process to go through the birth pains of SEIS as an open data construct, through to the dissemination of various spatial datasets and the first open portals pertaining to the various regulatory directives.
\end{abstract}

Keywords: open data, Aarhus, SEIS, INSPIRE, Malta, data interoperability, geoportal, LIDAR, spatial data, integration.

\section{The Long and Winding Road}

\subsection{Johnny Appleseed's Legacy}

Access to data posited many a dilemma for systems integration and dissemination. The transitional process from data to information to knowledge to action has been tackled from different perspectives, ranging from policymaking, through impact assessments to decision making exercises and recently to the integration of disparate datasets within integrated systems and eventually ported to the web for dissemination purposes. Each sector can be taken as a research topic in isolation, however the main 
fulcrum of the process revolves around the creation of a framework of policies and technologies that enable the exchange of spatial data across the different thematic and technological domains. This led to the establishment of a series of data-management processes aimed at setting-up and maintaining information resources structures through Spatial Data Infrastructures (SDIs) with early investigative work on conceptualization and international initiatives by Masser and Craglia [1] [2] [3] [4]. The drive was enhanced with inter-organisational studies by Nedovic-Budic and Pinto [5] as well as the work of the individual persons who pushed the initiative [6] and the eventual creation of an established SDI framework [7] that was also taken up at international level by the Global Spatial Data Infrastructure Association [8] and at national level [9]. Not exclusively anchored to the generic data management disciplines, this process nonetheless finds broad scope in this field particularly due to availability of specialised tools employed in environmental monitoring and reporting.

This paper reviews the mythical Appleseed one-core-at-a-time process employed in the implementation of a shared environmental information system (SEIS) [10] for the Maltese Islands which emulated the seeding with sequential implementation measures. Through the implementation of an ERDF [11] project entitled "Developing National Environmental Monitoring Infrastructure and Capacity", Malta embarked on a process that points towards the implementation of an open data structure, with a main output being the delivery of a SEIS geoportal. The final output, based on a specific target to create a SEIS, based on the environmental themes of air, water, noise, radiation, soil and marine [12] [13] resulted in a comprehensive innovative system that serves as an initial launching pad for open data [14]. The steps taken outline a description of the basic data definitions, the legislative mechanisms, the international-reporting requirements, the tools available and projects that tackle the means to reach an open data construct.

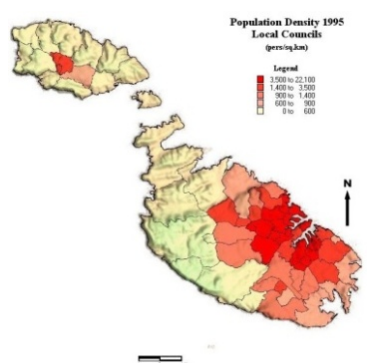

Fig. 1a. Population Density Imagemap, 1995

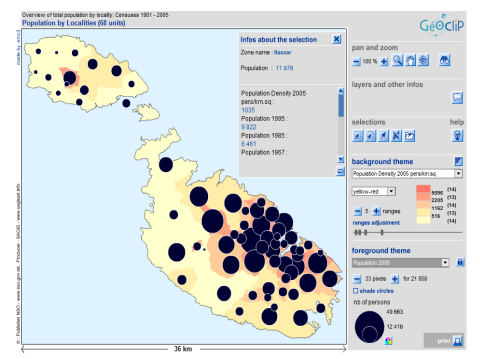

Fig. 1b. Census Interactive Map, 2005

Initial attempts to provide for an open portal [15] [16] [17], albeit limited by technology and/or lack of regulatory tools served to investigate user access and usage issues, with some basic Imagemap/GIS-client [18] (Figure 1a) and Interactive GIS [19] (Figure 1b) deliverables. The activities were based on the transposition of international directives, inclusive of the Data Protection Directive [20], the Public 
Sector Information Directive [21], the Aarhus Directive [22], the INSPIRE Directive [23], as well as the national initiative pertaining to the Freedom of Information Act [24].

\subsection{Fertile Fields}

A review of the main agencies involved in the spatial data exercise show that there exist a wide range of disparate datasets that are either non-conformant with INSPIRE or do not fall under the legislative tools mentioned above. The agencies involved include the main IT agency MITA (responsible for INSPIRE), MEPA (responsible for development planning and the environment, landuse/land cover, GMES, Copernicus, GEO, GEOSS, Aarhus and EEA-related reporting) and other entities.

A number of government departments and entities make use of the base map owned by MEPA although their GIS operating architecture differs from one to another, inclusive of the Agriculture Department, Fisheries Department, Land Registry, utilities such as Enemalta Corporation, the Water Services Corporation, cable and telephony companies (private), the Malta Resources Authority and the Transport Malta. Other structures include defense and civil protection, as well as a number of other departments, corporations and authorities that own data in various structures and which still need to conform to internationally recognized data standards. The INSPIRE Directive provides the framework for this structure but an NSDI (National Spatial Data Infrastructure) would ensure the integrative processing required for such a system. The Maltese Islands have embarked and delivered on the pilot domains emanating from the ERDF project [11] and developed a SEIS [25] in order to ensure conformity for monitoring and reporting.

\subsection{Trying to Make SENSE}

SEIS is not the first or only open-data conveyor for data, with such precursors including ENPI-SEIS (environmental protection project focusing on networking and open access through free tools) and a parallel project entitled ICT-ENSURE aimed at the management and dissemination of environmental information within a single informational infrastructure entitled SISE. Other initiatives include SEIS-BASIS (database structure on environmental monitoring programmes), NESIS (EEA-related state of play at national level), TESS (decision-making functional system), HUMBOLDT (aimed at the implementation of a European Spatial Data Infrastructure (ESDI), LENVIS (management systems for environment and health) and ORCHESTRA (risk-based management system for disaster reduction).

Spatially-targeted activities have also been implemented or are in such a phase, amongst which one can find the Copernicus Land Monitoring Services, the EEA's systems inclusive of the CLC runs (land-cover analysis), NATURA 2000, LUCAS and CCDA projects (protection zones), PLAN4ALL (landuse planning), GEO (earth observation), GMES (monitoring and environmental security), GEOSS, (system of systems), and GENESIS (synergic exercise between INSPIRE and the previous initiatives listed above that ensure integration of information in line with the single 
system envisaged in ICT-ENSURE). A lacunae identification initiative (GIGAS) was aimed to look at the gaps between these systems and also to point entities towards the requirements of a systems-approach data gathering structure (SANY) where sensors on the ground can gather information in real-time in a cohesive whole [12] [13].

SEIS established itself as a mainstay for such projects through its location-based services that bring together spatial, social and physical domains within a place-based structure. Such is made possible through its WMS, WFS, WCS and other services. The parallel SEIS-development, entitled SENSE aims to enable the sharing of European and national state of the environment and that allows for cross-country selection and support to SOE Online, the latter targeted to create a forum for the state of the environment.

\subsection{The Maltese Initiative}

Introducing a state to high-end information systems that encompass total national coverage is no mean task, even for such a small state as Malta with its 316 square kilometer area. Introducing a new paradigm in data creation and dissemination targeting spatial analysis points to a whole new reality [26] [27]. The Maltese Islands, through access to the European Regional Development Fund, managed to create a process aimed at environmental research that included innovative tool creation and scans that will help analysts to monitor the environment and related offences committed on the environment. In a process initiated by the author in 2006 and concluded in 2014, the SEIS-based activity resulted in the creation of fundamental datasets that also bring Maltese terrestrial and bathymetric baseline information to the public domain [25]. These activities have been carried out as part of a $€ 4.6$ million project, entitled Developing National Environmental Monitoring Infrastructure and Capacity, which also entailed the monitoring of air, water, soil, radiation, noise and marine themes [11]. This project was co-financed by the European Regional Development Fund, which provides $85 \%$ of the project's funding and the Government of Malta, which finances the rest under Operational Programme 1 - Cohesion Policy 2007-2013 - Investing in Competitiveness for a Better Quality of Life. Involving international experts from a number of countries and expert input from JRC, EEA, EC and other entities, whilst at a national scale, implementing partners included MEPA as project leader, the University of Malta, MRA, NSO and the Environmental Health Directorate.

SEIS in the Maltese Islands was based on a three-pronged approach; the alignment of its environmental structures to the varied legislative tools, the creation of integrated systems and the design of a reporting infrastructure. The main remit was to ensure such through the take-up of the SEIS initiative, where in 2008, the EU Commission published a Communication (COM (2008) 46 Final) "Towards a Shared Environmental Information System", which sets out an approach to modernise and simplify the collection, exchange and use of the data and information required for the design and implementation of environmental policy, according to which the current, mostly centralised systems for reporting are progressively replaced by systems based on access, sharing and interoperability. The overall aim was to maintain and improve 
the quality and availability of information required for environmental policy, in line with better regulation, while keeping the associated administrative burdens to a minimum.

Malta took part in the development of the SEIS, both at EU and national levels. The development of the national component of this system is particularly important for Malta, because it would streamline and simplify reporting processes to the EU an essential consideration for a relatively small national administration, which nonetheless has the same reporting requirements as much larger countries. But the benefits of the SEIS for Malta are not limited to improved reporting procedures to the EU. At the national level, the system would simplify, reduce costs, and increase effectiveness at all stages of environmental data cycle. This, in turn, would translate into more and better quality information being available for a variety of purposes at a considerably lesser cost than is the case at present.

The project aimed to develop the Malta component of the Shared Environmental Information System at a time when MEPA's geoportal (mapserver) was not deemed to be a comprehensive environmental information system. This project was tasked with an analysis of the current systems in place to process environmental monitoring data and data flows required, the design of the SEIS for Malta, and the development of such a web-based environmental information system. The project had to result in the creation of a web-based environmental information system, on the basis of existing platforms, as well as on the basis of any other additional platforms and components that may be required, to achieve full interoperability and functionality of the Maltese component of the SEIS, in line with the applicable guidelines and best practices in this field. The deliveries had to include a web-based GIS dedicated to environmental monitoring data incorporating MEPA's aerial orthophotos and basemaps available at the start of the project in 2010, as well as newly acquired satellite imagery, oblique aerial imagery, LiDAR terrain datasets and bathymetric data acquired through the ERDF project, of which the SEIS component was a part. Moreover, the SEIS had to be developed using an ArcGIS Server platform, based on system migration from an ArcInfo database to an ArcGIS geodatabase structure. This issue was set out due to the perceived need to fit such a system within the organisation's requirements at the time, which in turn could have also resulted in its main limitation, due to cross-system incompatibility as against a full-open structure. Also, the tendering process as such, limited the possibilities for alternate and innovative developments. One main issue concerned the need for the SEIS to be a modular and scalable system which is flexible to meet the varying demands of usage and applications over time.

The deliverables [11] were structured in a phased approach that sought to actuate:

- A review report on all requirements and parameters for the development and operation of the Maltese component of the SEIS and a proposal for the design and development of the SEIS;

- A report on the proposed ArcGIS geodatabase design for the SEIS based on an ArcGIS server architecture; 
- A prototype and pilot of the SEIS implemented and tested;

- A final version of the customised SEIS with a dedicated geoportal implemented and put into operation following feedback on the previous phase.

\section{They Came Before}

The ERDF project SEIS component was one in a series of initiatives that set the stage for this encompassing system. With initiatives such as the Census web-mapping project [28], the National Protection Inventory [29] and the SEIS-precursor Ambjent project [16], the process entailed the move from an image-mapping system (Figure 2a) to an early interactive prototype system. Such was based on the creation of spatial entities and attribute designations that were integrated with digitised card material (Figure 2b), integrated with pseudo-3d graphical interfaces (Figure 2c) and eventually to dynamic query systems (Figure 2d).

The dissemination technologies available at the time were used as surrogates towards this advanced system with data integration proposed through accessibility made possible by Image-Maps and map-server options. The resultant information system was envisaged to deliver a layered approach where users could access data that is available in an immersive clickable scenario through direct linking to spatial entities (points, lines, areas).

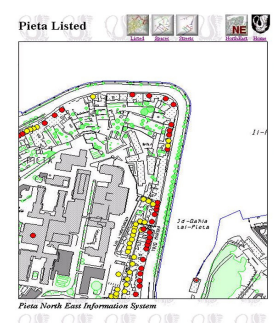

Fig. 2a. Imagemap 1996

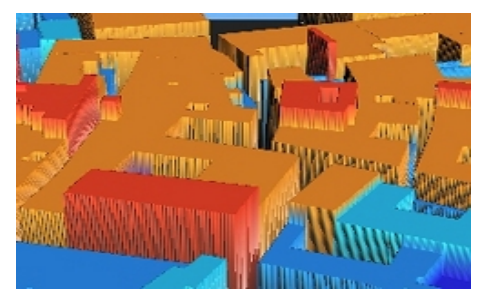

Fig. 2c. 3D extrusion

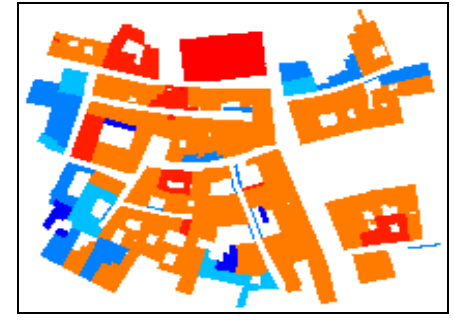

Fig. 2b. GIS layer

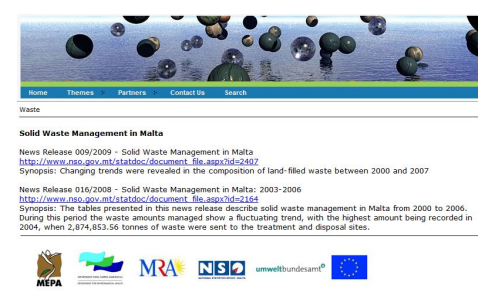

Fig. 2d. Query Interface 
In addition, the system would incorporate links to multimedia, imagery, walkthroughs, thematic data and access to a dynamic array of live information systems. The case was the same for the subsequent Census mapping exercises, the MEPA mapserver (Figure 3a), the Plan4All geoserver (Figure 3b), amongst others, however few had yet to envisage a system as proposed by SEIS, which was only made possible through the foundation laying of the implementation rules laid out by INSPIRE, Aarhus and the SEIS initiative.

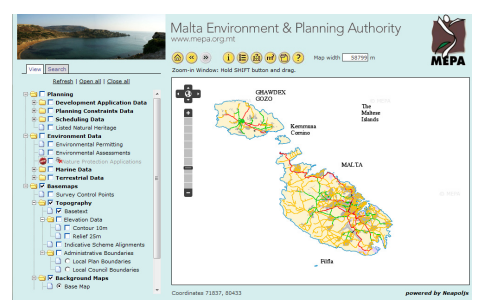

Fig. 3a. MEPA mapserver

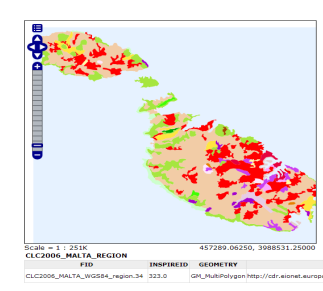

Fig. 3b. Plan4All geoserver

\section{Implementing SEIS}

\subsection{A 6-Stepped Approach}

With Malta being one of the first countries to initiate SEIS implementation, the aim was one to deliver information interoperability. It aimed to upgrade the methods employed to gather data, to streamline the reporting processes, to introduce implementation rules and to create a spatial data infrastructure as well as launch a visualisation and dissemination tool. The main aim was to develop data management and ingestion systems, allow for online data editing options, allow for data export and metadata viewing. In addition the system had to ensure that the country did not need to reinvent the wheel every time an information packet is requested from the EU and international conventions but would develop a search tool for the metadata and in turn enable automated reporting processes as required, particularly the European Environment Agency priority dataflows, always in line with INSPIRE, Aarhus and other legislative tools.

A 6-Step methodology was adopted [12] [13] to ensure the base setting for the SEIS:

1. Analysis of the target Data Model (INSPIRE Data Specifications and EEA reporting schemas)

2. Analysis of the Source Data (MEPA)

3. Conceptual design of the geodatabase

a. to include all the INSPIRE elements for which a correspondence with the source data has-been found 
b. to include all the additional elements not existing in the INSPIRE data model but present in the source data

c. to include the INSPIRE elements not existing in the source data

d. to include all the elements existing in the EEA reporting schemas

4. Preparation and filling-in of the matching table (MT)

5. Creation of the geodatabase structure, using different tools, according to the theme concerned

6. Import of the geodatabase in SQL Server (provided also an ESRI geodatabase for each theme, as an additional resource available).

Table 1. Standards \& Technologies

\begin{tabular}{|l|l|}
\hline Standard & Description \\
\hline OGC WMS & $\begin{array}{l}\text { A Web Map Service (WMS) is a standard protocol for serving } \\
\text { georeferenced map images over the Internet that are generated by a map } \\
\text { server using data from a GIS database. The specification was developed } \\
\text { and first published by the Open Geospatial Consortium in 1999. }\end{array}$ \\
\hline OGC WMS - T & $\begin{array}{l}\text { A WMS server can provide support to temporal requests. This is done by } \\
\text { providing a TIME parameter with a time value in the request. WMS } \\
\text { specifies that the basic format used for TIME requests is based on the ISO } \\
\text { 8601:1988(E) "extended" format. }\end{array}$ \\
\hline OGC WFS & $\begin{array}{l}\text { The Open Geospatial Consortium Web Feature Service Interface } \\
\text { Standard (WFS) provides an interface allowing requests for geographical } \\
\text { features across the web using platform-independent calls. }\end{array}$ \\
\hline ANSI SQL & $\begin{array}{l}\text { The Open Geospatial Consortium Web Coverage Service Interface } \\
\text { Standard (WCS) provides an interface allowing requests for geographical } \\
\text { coverages across the web using platform-independent calls. }\end{array}$ \\
\hline INSPIRE & $\begin{array}{l}\text { INSPIRE is "an EU initiative to establish an infrastructure for spatial } \\
\text { information in Europe that will help to make spatial or geographical } \\
\text { information more accessible and interoperable for a wide range of } \\
\text { purposes supporting sustainable development". }\end{array}$ \\
\hline Z39.50 is a client-server protocol for searching and retrieving \\
information from remote computer databases. It is covered by \\
ANSI/NISO standard Z39.50, and ISO standard 23950. The standard's \\
maintenance agency is the Library of Congress. Z39.50 is widely used in \\
library environments and is often incorporated into integrated library \\
systems and personal bibliographic reference software. Interlibrary \\
catalogue searches for interlibrary loan are often implemented with \\
Z39.50 queries.
\end{tabular}

Source: Bonozountas, M., and Karampourniotis, I., (2013), p. 15 
The resultant system had to deliver a SEIS portal that conformed to international standards, conditions and technologies set out by the same legislative and working documents described earlier. Table 1 describes the standards and technologies identified for the SEIS-Malta portal [13].

\subsection{The Resultant Interface}

Learning from the outcomes of the precursor exercises, particularly the Plan4All project, which had indicated that it was sometimes difficult to bring together the different datasets across the different thematic social and physical fields and required stringent rules for inter-operability, the SEIS project learned from the need to 'listen' to the outcomes of conceptual models that served as a veritable exercise in comprehensiveness due to their holistic and detailed approach. The main issues in the Maltese context deal with the fact that the conceptual models reflect their name: they are concepts that require tweaking and need to consider different levels of conformity: local-national (NUTS 2,3,4,5 as compared to NUTS 1) and national-super-national (NUTS 1 as compared to EU). The CLC1990-2000-2006 runs proved that this can be done if one uses a harmonisation of the top-down (model) and bottom-up approach (users-data creation), whilst remaining loyal to the legislative requirements.

Based on a GeoNetwork Open Source (GNOS) approach, the Malta SEIS webportal delivered various services that went beyond the precursors of ambjent.org.mt and the census webmaps and also beyond the development of the Plan4All geoserver. The new seismalta.org.mt portal was resultant of the ERDF project.

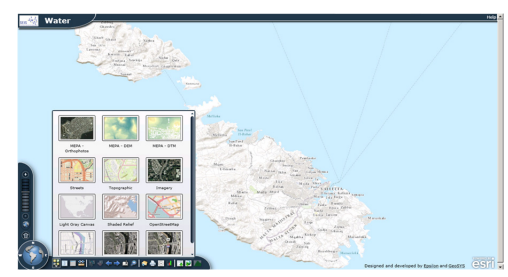

Fig. 4a. Basemapping

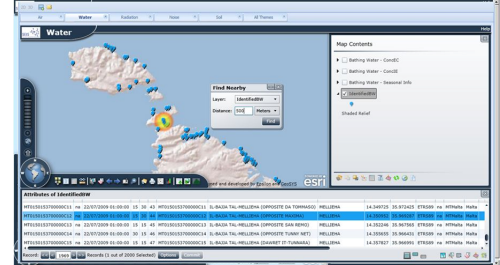

Fig. 4c. Data outputs

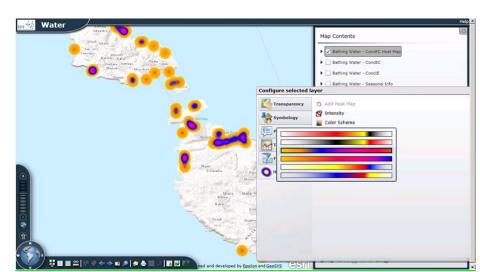

Fig. 4b. Heatmaps

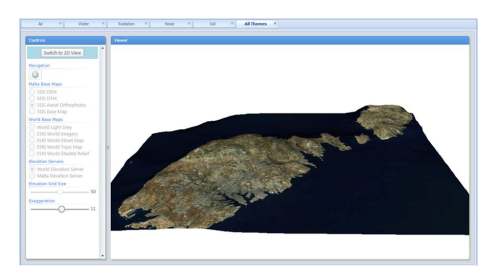

Fig. 4d. 3D viewer 
SEISmalta.org.mt offers a veritable plethora of services, made possible through the ERDF geoportal, which requires the ArcGIS Silverlight API, employing visual tools, though the latter has served many a criticism by users who do not wish to install the tool or use other platforms, something that needs to be rectified over the updated versions of the portal, especially if it needs to be full open. The services cover: Download Services (Figure 4a), Ingestion Service, a Data Quality Service, a Sensor Observation Service for real-time data input, as well as a Feedback Service to the geoportal administering agency. In addition, the SEIS output includes a reporting Notification Service, a Registry Service for new databases, a Reporting Service, which service queries the database and prepares reporting outputs for EC and national requirements' consumption. Figure 4 depicts the Seismalta portal's basemaps (Figure 4a), thematic heatmaps (Figure 4b), data portal (Figure 4c) and a 3D topographic viewer (Figure 4d).

\subsection{Post-SEIS}

Post-SEIS project conclusion, the entities are in the process of establishing a wider national inter-agency approach, where the main tenet is based on the underlying strategy for data management built on a 'gather-once / use-many' approach. Such ensures that data is gathered once but used by all without incurring further costs, access and implementation bottlenecks, whilst at the same time employing one tool for dissemination services through an enhancement of the SEIS portal. This proposal looks at the setting up of an organisation through a two-phased approach where an entity is tasked with implementing short-term targets, such as the creation of a SEISbase-data structure for all entities and in the long-term tasked with the integration of all these systems into one entity with dedicated thematic expertise across the diverse GI-enabled domains.

Phase I should ensure the migration from the current isolated-entities system to one where the datasets are harmonised, aligned and prepared in line with the SEIS process for the eventual integration that would be required in Phase II. The Phase I concept envisages a scenario where the setup would be similar to the current system of individual-entity ownership where the entities are defined as "owners of data" meaning that each department, authority, corporation or organisation is responsible for collecting, maintaining and managing data relevant to the running of its activities and operations. This data will be shared with other entities in an open mode and free disseminated through the SEIS-based tools. The advantages lie in the fact that:

- the data is maintained by the owner of the information;

- updating of the system is done in an "informed" or more professional manner rather than straight forward data entry;

- the organisation itself and its officials maintaining the information are made responsible and accountable for the data;

- this system also allows the other entities to create their value-added data on to the same datasets which the 'guardian' entity can then decide to implement as part of that dataset. 
It is imperative that each dataset has to comply with legislative implementation rules, even for those that do not fall under the diverse Directives. It is vital that the data inputted in the system, once the necessary data collection exercise is carried out, will be almost completely error free. Thus, it is of the utmost importance, that the project is set in the right perspective and that there are clear guidelines and standards to which all participants within the system would have to abide by. This at a time when another MED project entitled HOMER [30] is specifically focusing on the Open Data theme, as based on the Public Sector Information Directive and its update. In addition, new issues are cropping up with the emergent EU level e-Reporting systems ensconced within the Structured Implementation and Information Framework (SIIF) concept [31]. Such a situation calls for an interesting development that places the Islands at an advantage for takeup through the enhancement of the SEIS geoportal into a wider thematic construct, going beyond environmental domains into highly integrated societal systems.

\subsection{Tasting the Apples}

The project's trust serves its main purpose only if its functionality is translated into tangible outcomes and usability. The SEIS output has been both augured and criticised by users in terms of ease of use and requirements to install additional tools due to browser constraints. The main users were professionals in the field and students who regularly reviewed the site outputs for their research studies. Nongovernmental organisations welcomed the initiative though highlighted the issue that now that data was being made accessible, it was difficult to interpret without expert input. The latter issue is interesting since it posits a state of affairs that users may not be willing to take up new technologies beyond their wow-factor, that data and especially open-data can be overwhelming due to its large volumes, that users find themselves lost in receipt of data even when supplied with lineages and all metadata. Interestingly, when challenged with the fact that data is shared by all and that it is available in real or quasi-real time, users showed both disbelief and worry, ironically due to the fact that they must now criticise themes based on scientific facts as against opinion or second-hand comments from reports; NGOs and experts alike now have the tools and the data to reach informed opinions on their say and offer data-backed feedback for social-change initiatives. This process also serves to increase the number of researchers who were previously holding back due to access issues.

Having sowed the initial SEIS portal in the Maltese Islands, it is time to compare and contrast the system with the new developments in SEIS coming out from the EEA, the Austrian Umweltbundesamt and similar initiatives.

\section{Conclusion}

In conclusion, the Malta SEIS geoportal depicts an integrated system based on a geodatabase that includes those INSPIRE elements where source data has been found in conjunction with other elements that were not required by INSPIRE but were 
available within the source dataset. The basic requirements emanating from the ERDF project requirements were satisfied, whilst additional services as yet not possible due to space and bandwidth restrictions have been provided through alternative measures such as physical pickup of the data that measures at $600 \mathrm{~Gb}$ and counting.

In reviewing the process to establish a framework for the development of the system in Malta, the project established various factors, mainly on the potential uses of such a system, the need for user consideration and feedback as well as the need to ensure that there is conformity to the regulations that guide such developments.

With limitations imposed by the same procedural process as outlined in this paper, such a project would have overcome benefitted from more 'openness' on systems choice, creation of various parallel tools for comparative analysis of the outputs and a critical approach to similar systems under development in other countries. The latter, though entering the scene late in the day, would have co-benefitted from the successes and pitfalls of the Malta SEIS.

However, the SDI concept and its SEIS initiate is a phenomenon that will not go away, as the cores have been planted and the roots established.

\section{References}

1. Masser, I.: All shapes and sizes: the first generation of national spatial data infrastructures. International Journal of Geographical Information Science 13(1), 67-84 (1999)

2. Masser, I.: GIS Worlds - Creating Spatial Data Infrastructures. Urisa Journal, 1-3 (2005)

3. Masser, I.: Some Priorities for SDI Related Research. In: Proceeding of the FIG Working Week 2005 and GSDI-8: From Pharaohs to Geoinformatics, Cairo, Egypt, April 16-21 (2005)

4. Craglia, M., Masser, I.: Geographic information and the enlargement of the European Union: Four national case studies. URISA Journal 14(2), 43-52 (2002)

5. Nedovic-Budic, Z., Pinto, J.K.: Information sharing in an interorganizational GIS environment. Environment and Planning B: Planning and Design 27(3), 455-474 (2000)

6. Craig, W.J.: White Knights of Spatial Data Infrastructure: The Role and Motivation of Key Individuals. Urisa Journal 16(2), 5-13 (2005)

7. Janssen, K., Dumortier, J.: Legal Framework for a European Union Spatial Data Infrastructure: Uncrossing the Wires. In: Research and Theory in Advancing Spatial Data Infrastructure Concepts. ESRI Press, Redlands California (2007)

8. Douglas, G., Nebert, D. (eds.): The SDI Cookbook, Version 2.0 (Technical Working Group Chair, Global Spatial Data Infrastructure (GSDI) (2004), http: / /www.gsdi .org/ (accessed on April 14, 2014)

9. Farrugia, A.: Implications of EU Accession on Environmental Spatial Data: a Malta Case Study, unpublished MSc GIS Science dissertation. Manchester Metropolitan University, Manchester (2006)

10. European Commission: Shared Environment Information System, http: / / ec. europa.eu/environment/seis / (accessed on March 10, 2014)

11. Malta Environment \& Planning Authority: Developing National Environmental Monitoring Infrastructure and Capacity, MEPA, Floriana, Malta (2009)

12. Bonozountas, M., Karampourniotis, I.: MALTA-SEIS: Deliverable D2.1Report of Analysis and Detailed Proposal for SEIS, CT3067/2010 - 02, Malta (2012) 
13. Bonozountas, M., Karampourniotis, I.: MALTA-SEIS, Report of Analysis and Detailed Proposal for SEIS, CT3067/2010 - 02 D2_31-01-2, Marousi, Greece (2013)

14. MEPA: Service Tender for the Design of the Shared Environmental Information System (SEIS) and development of a web-based GIS interface, ERDF 156: Developing national environmental monitoring infrastructure and capacity 3067/2010, Floriana (2010)

15. MEPA: MEPA mapserver, http: / / www . mepa.org.mt/Planning/index.htm?MapServer.htm\&1 (accessed on February 29, 2014)

16. MEPA: Further Institution Building in the Environment Sector, http: / /www . ambjent. org . mt (accessed on March 15, 2014)

17. Formosa, S., Magri, V., Neuschmid, J., Schrenk, M.: Sharing integrated spatial and thematic data: the CRISOLA case for Malta and the European project Plan4all process. Future Internet 2011 3(4), 344-361 (2011)

18. NSO: Census of Population and Housing (1995), http: / /www. mepa.org.mt/Census / index.htm (accessed on February 29, 2014)

19. NSO: Census of Population and Housing (2005), http: / /www. mepa.org.mt/index.htm?links.htm\&1 (accessed on February 29, 2014)

20. Official Journal of the European Union: "Directive 95/46/EC of the European Parliament and of the Council of 24 October 1995 on the protection of individuals with regard to the processing of personal data and the free movement of data," L 281, 23/11/1995, (24 October 1995)

21. Official Journal of the European Union: Directive 2003/98/EC of the European Parliament and of the Council of 17 November 2003 on the re-use of public sector information, L 345, 31/12/2003 (November 17, 2003)

22. Official Journal of the European Union: Directive 2003/4/EC of the European Parliament and of the Council of 28 January 2003 on Public access to environmental information and repealing Council Directive 90/313/EEC (Aarhus), L 041, 14/02/2003, pp. 0026-0032 (January 28, 2003)

23. Official Journal of the European Union: Directive 2007/2/EC of the European Parliament and of the Council of 14 March 2007 establishing an Infrastructure for Spatial Information in the European Community (INSPIRE), L108, vol. 50 (April 25, 2007)

24. Government of Malta: Freedom of Information Act, CAP496, Valletta, Malta (September 1, 2012)

25. MEPA: Malta SEIS, http://www.seismalta.org.mt (accessed on February 29, 2014)

26. Formosa, S., Sciberras, E., Formosa Pace, J.: Taking the Leap: From Disparate Data to a Fully Interactive SEIS for the Maltese Islands. In: Murgante, B., Gervasi, O., Misra, S., Nedjah, N., Rocha, A.M.A.C., Taniar, D., Apduhan, B.O. (eds.) ICCSA 2012, Part II. LNCS, vol. 7334, pp. 609-623. Springer, Heidelberg (2012)

27. Martirano, G., Bonazountas, M., Formosa, S., Nolle, M., Sciberras, E., Vinci, F.: INSPIRE EF Data Specifications to develop the SEIS-Malta Geodatabase for the Air Quality data management. In: INSPIRE Conference, Istanbul, Turkey (June 2012)

28. Formosa, S.: Coming of Age: Investigating the Conception of a Census Web-Mapping Service for the Maltese Islands. Unpublished MSc thesis Geographical Information Systems. University of Huddersfield, United Kingdom (2000), http: / / www.tcnseurope.org/census/1995/index.htm (accessed on February 29, 2012) 
29. Borg, M., Formosa, S.: The Malta NPI project: Developing a fully-accessible information system. In: Wise, S., Craglia, M. (eds.) GIS and Evidence-Based Policy Making, Innovations 10. Taylor \& Francis, Boca Raton (2008)

30. HOMER: HOMER MED project, http://www.homerproject.eu (accessed on March 15, 2014)

31. European Commission: Communication on Implementing EU environment legislation Questions \& Answers,

http: / / europa.eu/rapid/press-release_MEMO-12-159_en.htm (accessed on March 15, 2014) 